\title{
A Controlled Study Of Formal Thought Disorder in Children with Autism and Multiple Complex Developmental Disorders
}

\author{
Rutger J. van der Gaag, ${ }^{1}$ Rochelle Caplan, ${ }^{2}$ Herman van Engeland, ${ }^{3}$ F. Loman, ${ }^{4}$ and \\ Jan K. Buitelaar ${ }^{1}$
}

\begin{abstract}
Along with well-defined categories in classification systems (e.g., autistic disorders and attention-deficit/hyperactivity disorder (ADHD)), practitioners are confronted with many children showing mixed forms of developmental psychopathology. These clusters of symptoms are on the borderlines of more defined categories. The late Donald Cohen proposed heuristic criteria to study a group defined by impaired social sensitivity, impaired regulation of affect, and thinking disorders under the name multiple complex developmental disorders (MCDD). Although these children meet criteria for pervasive developmental disorder-not otherwise specified (PDD-NOS), they have additional important clinical features, such as thought disorder. After highlighting similarities and differences between MCDD and comparable groups (e.g., multidimensionally impaired children), this paper presents the findings of a study comparing formal thought disorder scores in children with MCDD to children with autism spectrum diagnoses, such as autistic disorder (AD), and to children with nonspectrum diagnoses, such as ADHD and anxiety disorders.

Methods: Videotaped speech samples of four groups of high-functioning, latency-aged children with MCDD, AD, ADHD, and anxiety disorders were compared to a control group of normal children using the Kiddie Formal Thought Disorder Rating Scale (K-FTDS).

Results: High formal thought disorder scores were found both in the AD and MCDD groups, low rates in the ADHD groups, and no thought disorder in the anxiety disorder and normal control groups. The severity of formal thought disorder was related to verbal IQ scores within the AD and MCDD groups.

Conclusion: High formal thought scores in children with complex developmental disorders, such as $A D$ and MCDD, appear to reflect impaired communication skills rather than early signs of psychosis.
\end{abstract}

\footnotetext{
${ }^{1}$ University Medical Centre St. Radboud Nijmegen-Academic Centre for Child and Adolescent Psychiatry, Nijmegen, The Netherlands.

2Department of Psychiatry and Biobehavioral Sciences, UCLA, Los Angeles, California.

3University Medical Centre Utrecht-Department of Child and Adolescent Psychiatry, Utrecht, The Netherlands. ${ }^{4}$ GGZ Regio, Breda, the Netherlands.
} 


\section{INTRODUCTION}

A LONG WITH DEFINED CATEGORIES, Diagnostic and Statistical Manual of Mental Disorders, 4th edition, text revision (DSM-IV-TR) includes so-called "Not Otherwise Specified (NOS)" categories meant for lesser variants or borderline conditions to the clearly defined cases. The NOS subcategory for pervasive developmental disorder (PDD-NOS) was introduced in DSM-III-R (1986). Cohen et al. (1986) were concerned that only two categories for autism in DSM-III-R would be too few to provide a more fine-tuned description of subgroups within what is now commonly named the Autistic Spectrum. These subgroups had been identified by on-cluster analyses on large groups of children with "atypical" behavior (Prior et al. 1975; Dahl et al. 1986).

Cohen et al. suggested that two new categories should be introduced in DSM-IV. The first one would be Asperger's disorder (Asperger 1944; Wing 1981), referring to individuals with developmental problems in the areas of social reciprocity, communication, and rigid and restricted patterns of behavior. These individuals differed from the classical Kanner Autism in that they developed language at typical stages (yet not the adequate pragmatics) and they had motor clumsiness and intellectual preoccupations more than motor stereotypies. This category was finally included in DSM-IV, but the criteria did not include many of the features Asperger actually described (Miller and Ozonoff 1997).

The second proposal (Cohen et al. 1986; Cohen et al. 1991) on multiple complex developmental disorders (MCDD) was not included in DSM-IV. It was a heuristic proposal aimed at promoting research on a category well known in clinical practice (Green and Jones 1998) and clearly emerging as a distinct cluster in the analysis of the children with atypical developmental (Dahl et al. 1986). These children had previously been described under different diagnostic labels, including "borderline children (Pine 1974; Bemporad et al. 1982; Vela et al. 1983), Schizoid Personality in Childhood (Wolff 2003), and schizotypal children (Nagy and Szatmari 1986). Ironically, it had been included in DSM-III (American Psychiatric Association 1980) with the label "Childhood-Onset Pervasive Developmental Disorder" but, for reasons that are not clear, was not continued into DSM-III-R and thus not considered in DSM-IV. All these labels recognized children who could be placed "in the borderlands of autism." They share with more classically autistic children a lack of social sensitivity and empathy, but yet differ importantly from autistic children. Where children with "classic Kanner autism" lack imagination, these atypical children tend to get carried away by a far too-vivid imagination that blurs their reality testing. The defining criteria for MCDD include: (1) consistently impaired social behavior and sensitivity; (2) impaired regulation of affective state; and (3) impaired cognitive processing "thinking disorder."

The discriminative potential of these criteria in categorizing these children reaches sensitivity and specificity levels comparable to those for autistic disorder (Buitelaar and Van der Gaag 1998) (Table 1).

The face validity of the concept was demonstrated in a series of independent studies (Towbin et al. 1993; Van der Gaag et al. 1995). The predictive validity is high (Van der Gaag 1993). There is longitudinal persistence of symptoms in the area of development of social reciprocity and thinking disorders. The extreme problems in the regulation of affective states are less prominent in adolescents and adults. There is a marked shift towards symptoms from the schizophrenia spectrum in adults, with up to $17 \%$ of the cases meeting criteria of schizophrenia after one or several psychosic episodes and over $60 \%$ meeting the criteria for schizoid or schizotypal personality disorder (Van Engeland and Van der Gaag 1994). Other differences come from studies on the stress-regulation characteristics in the MCDD group (Kemner et al. 1999; Jansen et al. 2003) that show marked differences in these areas between individuals with autistic disorder and individuals with MCDD who, on these dimensions, are more similar to adults within the schizophrenia spectrum.

The third characteristic of MCDD children includes "disordered thinking," which is com- 
Table 1. Most Parsimonius and Effective Scoring Rule for MCDD (to be used for Research)a

1. Impaired regulation of states of mind and anxieties

A. unusual or peculiar fears and phobias, or frequent idiosyncratic or bizarre anxiety reactions

B. recurrent panic episodes or flooding with anxiety

C. episodes of behavioral disorganization punctuated by markedly immature, primitive, or violent behavior

2. Impaired social behavior

A. social disinterest, detachment, avoidance, or withdrawal

B. markedly disturbed and/or ambivalent attachments

3. The presence of thought disorder

A. irrationality, magical thinking, sudden intrusion on normal thought processes, bizarre ideas, neologisms, or repetitions of nonsense words

B. perplexity and easy confusability

C. overvalued ideas, including fantasies of omnipotence, paranoid preoccupations, overengagement with fantasy figures, and referential ideation

Note. A total of five (or more) items from (1), (2), and (3), with at least one item from (1), one item from (2), and one item from (3).

$\mathrm{MCDD}=$ multiple complex developmental disorders.

aSee entry in References for Buitelaar and Van der Gaag (1998).

monly thought to be specific to schizophrenia. However, to date, no studies have examined thought disorder in MCDD and whether the thought processes of these MCDD children are similar to or different from those of individuals with autistic disorder and individuals with "non-PDD" severe behavioral and emotional problems.

\section{Formal thought disorder}

Thoughts are mental processes that are conveyed by language and characterized by both the content and form in which they are presented. Although clinicians often wonder if impaired language and "thought disorder" are equivalent or distinct, the assumption that language and formal thought are "perfectly" correlated is not justified (Lecours and VanierClément 1976). In an early study on the measurement of thought disorder, Andreasen (1979) stated that "one cannot in fact infer with certainty that normal language reflects normal thinking or, conversely, that disordered language reflects disordered thinking." Within the typical clinical practice of psychiatry, however, the term "formal thought disorder" is most often used as synonymous with "disorganized speech." She considered thought and language to be intertwined. In contrast, arguing that language and thought disorder are both conceptually and empirically discernable, Holzman et al. (1986) viewed language as the mediator of thoughts and defined thought disorder as impaired organization and processing of thoughts.

Although once considered pathognomic of schizophrenia, formal thought disorder is not found in all schizophrenic adults and children, and it occurs in other forms of psychoses, such as mania (Andreasen et al. 1974; Jampala et al. 1989), as well as in nonpsychotic disorders (Caplan et al. 2001; Caplan et al. 2002). Several authors also found milder instances of thought disorder in the nonpsychotic relatives of schizophrenic adults (Docherty and Gordinier 1999; Kinney et al. 1997; Vollema and van den Bosch 1995).

\section{Thought disorder in children}

Studies on thought disorder in children have been sparse. An early description of "formal" thought disorder or the manner in which thoughts are conveyed to the listener is found in Kolvin et al. (1971), who reported that 60\% of the children with "early onset psychosis" showed disorders of association, derailment of thought, or were "talking past the point." Russell et al. (1989) later described thought disorder in only $40 \%$ of a sample of 33 prepubertal schizophrenic children. Caplan et al. (1989) 
noted that, although based on meticulous and thorough clinical evaluations, these earlier studies did not clarify how thought-disorder signs were operationalized for use with children of different ages. These researchers demonstrated that with operationalized criteria of formal thought-disorder signs, such as illogical thinking and loosening of associations, formal thought disorder may be a "normal" phenomenon in healthy children with a mental age of 7 years and below. Younger children with schizophrenia (Caplan et al. 2000), ADHD (Caplan et al. 2001), and epilepsy (Caplan et al. 2002) also had significantly more illogical thinking and loosening of associations than older children with these diagnoses. These developmental findings led to the conclusion that onset of schizophrenia, ADHD, and epilepsy during middle childhood impacts the ongoing development of children's ability to formulate and organize their thoughts coherently. The complex skills involved in organizing and presenting one's thoughts to the listener in a coherent manner develop from early childhood through adolescence and involve cognition, language, and pragmatic skills (see review in Caplan 1994). In light of the vast body of evidence for deficits in the pragmatics of language behavior in autistics (Watson 1988; Baron-Cohen 1988), so-called formal thought disorder in autistic children could be quite easily identified. Nevertheless, there are only two studies on the occurrence of thought disorder in subjects with autism. In a study with autistic adults, Rumsey et al. (1986) reported a high incidence of signs of formal thought disorder, such as poverty of speech, poverty of content of speech, and perseveration. Dykens et al. (1991) confirmed these results in an adolescent and adult autistic sample by finding high rates of poverty of content of speech, as well as other evidence for "cognitive slippage," such as incongruous combinations and fabulizing.

Although thought disorder appears to be a nonspecific clinical finding in psychiatric disorders, the profile of cognitive and linguistic correlates of formal thought disorder differs in these disorders. Schizophrenic children have formal thought disorder irrespective of their cognitive and information-processing deficits
(Caplan et al. 2001). In children with ADHD, the severity of thought disorder is related to both global and specific attentional deficits in children (Caplan et al. 2001). In children with epilepsy with a normal IQ, there are subtle global cognitive deficits (Caplan et al. 2002).

\section{Aims of this study}

This study determined whether formal thought disorder occurs in children with MCDD and if the clinical, cognitive, and linguistic profile of thought disorder in these children differentiates them from psychiatric controls such as ADHD, anxiety disorders, and autistic children, as well as from typically developing children. We included a control group of children with anxiety disorder because of the high level of anxiety and affective symptoms found in children with MCDD.

Based on the previously reviewed studies, we expected that MCDD children (with more imagination and disorders of content of thought) would exhibit features of "positive" formal thought disorder (i.e., illogical thinking and derailment or loose associations), whereas autistic children would be more likely to display "negative" formal thought disorder (i.e., poverty of speech or poverty of content of speech). We also predicted that the thought disorder of the children in the study would be related to both mental and verbal age.

\section{METHODS}

\section{Subjects}

The 72 children who participated in this study were distributed in five diagnostic groups. The five groups were matched by verbal age (Chronological Age $\times$ Verbal IQ/100). Children with a verbal, performance, or total IQ of less than 70 were excluded.

The four child psychiatric groups of children were recruited from referrals to the Utrecht Department of Child Psychiatry (Utrecht, The Netherlands) and to a child guidance clinic in Maastricht. DSM diagnoses were established after extensive diagnostic procedures. These included a developmental history, a parent in- 
terview, a child psychiatric examination with the Kiddie-Schedule for Affective Disorders and Schizophrenia (K-SADS) and psychological investigations. All diagnoses were independently made and verified by two psychiatrists (RJVdG and FL). Only cases with complete agreement were retained. To make a clear distinction between the children with autistic disorder and the MCDD group, all autistic children met more than six positive criteria on DSM-IV and, moreover, fulfilled the very restrictive DSM-III (American Psychiatric Association 1980) criteria for "Infantile Autism" without any comorbidity. The MCDD group was composed of children who received a DSM-IV classification of PDD-NOS and met the criteria for MCDD (Cohen et al. 1991; Buitelaar and Van der Gaag 1998). The ADHD children met the DSM-IV criteria for ADHD, as well as "hyperactivity" scores within the clinical range (i.e., above the 98th percentile) on parent's questionnaires (Child Behavior Checklist CBCL, Dutch Version; Verhulst 1985) and the Teachers Conners Questionnaire (Dutch Version; Blöte and Curfs 1986). Two ADHD boys also had a classification of chronic motor tics. No other comorbidity was classified. A group of children with anxiety disorder was recruited from a child guidance clinic in Maastricht (Southern Netherlands). This group was composed of children who had a normal development and were diagnosed after adjustment problems to external stress. For these children, only a verbal IQ was available. The normal controls were recruited from an elementary school in the Utrecht area and included only children with normal scores on the CBCL an average IQ on the WISC with a harmonious profile. (Children with a difference of more than 10 points on verbal and performance scores were excluded from the study.) The details of the population can be found in Table 2.

\section{Procedures}

The Story Game procedure developed by Caplan et al. at the University of CaliforniaLos Angeles (UCLA; Los Angeles, CA) was followed (Caplan et al. 1989).

The Kiddie Formal Thought Disorder Story Game (Caplan et al. 1989)

A trained interviewer administered the three parts of Story Game (Caplan et al. 1989)

Table 2. Characteristics of the Diagnostic Groups

\begin{tabular}{|c|c|c|c|c|c|c|}
\hline \multirow[b]{2}{*}{ Groups } & \multirow[b]{2}{*}{$n$} & \multicolumn{2}{|c|}{ Gender } & \multirow[b]{2}{*}{$C A^{a}$} & \multirow[b]{2}{*}{$V I Q^{b}$} & \multirow[b]{2}{*}{$V A^{c}$} \\
\hline & & $M$ & $F$ & & & \\
\hline Autistic Disorder (AD) & 14 & 13 & 1 & 10.09 & 85.28 & 8.08 \\
\hline SD & & & & 2.02 & 19.52 & 1.26 \\
\hline Multiple Complex & 20 & 19 & 1 & 10.02 & 90.45 & 9.01 \\
\hline Developmental Disorder (MCDD) & & & & 1.60 & 10.80 & 1.71 \\
\hline \multicolumn{7}{|l|}{ SD } \\
\hline Attention-deficit/hyperactivity & 13 & 13 & 0 & 9.05 & 97.61 & 9.02 \\
\hline disorder (ADHD) & & & & 1.40 & 6.69 & 1.37 \\
\hline \multicolumn{7}{|l|}{ SD } \\
\hline Anxiety disorders (ANX) & 10 & 4 & 6 & 9.06 & 111.00 & 10.07 \\
\hline $\mathrm{SD}$ & & & & 1.01 & 5.71 & 1.33 \\
\hline Normal controls (NC) & 15 & 10 & 5 & 9.10 & 104.66 & 10.03 \\
\hline SD & & & & 1.01 & 7.01 & 1.33 \\
\hline Entire group (EG) & 72 & 59 & 13 & 10.00 & 96.55 & 9.02 \\
\hline SD & & & & 1.5 & 14.19 & 1.55 \\
\hline
\end{tabular}

NS = not significant; SD = standard deviation.

aKruskal-Wallis: NS.

bKruskal-Wallis: $\chi^{2}$ 32.4879; $p<0.0001$; Mann-Whitney U: AD, MCDD < ADHD < Normals < ANX.

cKruskal-Wallis: NS for the AD/MCDD/ADHD and Normals.

Only the ANX group had a significantly $(p=0.02)$ higher verbal age. 
(Dutch translation; Van der Gaag 1993). In the first and last part, the child heard an audiotaped story: The first story is confusing, as it is about a boy dreaming about a friendly ghost. The last story is about a boy who is excluded from his group of friends and badly teased. The child was instructed to retell the tale, and was also asked a series of open-ended, standardized questions on each story. In the second part of Story Game, the child was asked to make up his or her own story chosen from four topics (the horrible hulk, a witch, a very disobedient child, or a very unhappy child). The topics of all the stories were chosen because they appeal to the fantasy of the child and are likely to elicit pathological thought content in children. This whole procedure was videotaped.

\section{The Kiddie Formal Thought Disorder Rating Scale (K-FTDS)}

Videotapes of the 20-30 minute Story Game were rated with the K-FTDS by two pairs of trained raters. The raters had no previous knowledge of the diagnoses of the children.

The following phenomena were scored according to the K-FTDS guidelines (Caplan et al. 1989):

- Illogical thinking (ILL) when the child: (1) used causal utterances in an inappropriate way, (2) presented the listener with unfounded and inappropriate reasoning in noncausal utterances, or (3) contradicted himself of herself within one to two utterances by simultaneously making and refuting statements.

- Loose associations (LA) were rated when the child changed the topic of conversation to a new unrelated topic without preparing the listener for the topic change.

- Poverty of content of speech would be scored if, in the presence of at least two utterances, the child did not elaborate on the topic.

An utterance would be rated as incoherence if the rater could not comprehend the contents of an utterance resulting from scrambled syntax.
Following the procedure used by Caplan et al. (1989), the scores used for the analysis were derived from these ratings, frequency counts for illogical thinking, and loose associations. The raw scores were divided by the number of utterances per minute produced by the child.

The first author was trained by R. Caplan. He subsequently trained four student raters. Their pilot ratings were supervised by $\mathrm{R}$. Caplan. The inter-rater reliability was tested on a sample of 5 autistic, $10 \mathrm{MCDD}, 5 \mathrm{ADHD}$, and 5 normal control children. We included more patients than normal children for calculation of the inter-rater reliability because of the low base rate of formal thought disorder in the latter group. The chance corrected kappa reliability statistic (Cohen 1968) was 0.70 for illogical thinking, 0.65 for loose associations, and 0.95 for utterance counts. These were considered acceptable, as the bias adjusted kappa of prevalence and bias adjusted kappa all ranged well above 0.80 .

\section{Data analysis}

Nonparametric statistics were used for the analysis, because the distribution of the parameters clearly deviated from a normal distribution. For each variable, the differences between the groups were evaluated with a Kruskal-Wallis one-way analysis of variance (ANOVA). Pairwise group comparisons were evaluated with a Mann-Whitney U test.

The correlations between the formal thought disorder scores and the full-scale IQ, verbal, and performance IQ, and the WISC-R factors Distractability, Perceptual Organization and Verbal Comprehension (Kauffman 1979), were calculated using the Spearman rank correlation. A significance level of 5\% was accepted.

\section{RESULTS}

The Story Game proved to be a useful method in our sample. Children from all diagnostic groups were interested in the stories, and were challenged to respond. The utterance counts (over the first 5 minutes) as a measure for the "verbal output" did not differentiate between the five groups (Table 3). 
Table 3. Utterance Counts in the First Five Minutesa

\begin{tabular}{lccc}
\hline & Mean & SD & Cases \\
\hline AD & 67.43 & 22.37 & 14 \\
MCDD & 68.45 & 16.20 & 20 \\
ADHD & 79.00 & 15.10 & 13 \\
ANX & 75.70 & 11.43 & 10 \\
Normal Controls & 76.73 & 7.83 & 15 \\
\hline
\end{tabular}

$\mathrm{AD}=$ autistic disorder; $\mathrm{MCDD}=$ multiple complex developmental disorders; ADHD = attention-deficit/hyperactivity disorder; $\mathrm{ANX}=$ anxiety disorders; $\mathrm{SD}=$ standard deviation.

aKruskal-Wallis one-way ANOVA: ns (not significant).

\section{K-FTDS diagnostic findings}

Across all groups, we found more ratings for illogical thinking (ILL) than for loose associations (LA) (Table 4), though these instances were least common in the normal children. Loose associations distinguished the groups more clearly. They did not occur even once in the normal controls or the anxiety-disordered children and were scored more than once in only 1 ADHD child. In contrast, more than two ratings of LA were common in the autistic and MCDD children (Table 3). Finally, incoherence and poverty of content of speech categories were not observed at all in the total sample of children.

In the group comparisons no differences were detected between children with autism and MCDD. The two groups (AD and MCDD) differed significantly from the three contrast groups on all three ratings (total FTD, ILL, and LA) (Tables 5, 6, and 7). The total FTD and ILL scores of the ADHD group clearly occupy an intermediate position between those of the autistic and the multiplex groups, compared to the anxiety disorder group and the normal groups. Unlike the autistic and multiplex and ADHD subjects, the anxiety disorder group and normal controls did not have loose associations. On the ILL scores, the ADHD differed significantly from the anxiety disorder group $(U=31 ; p<0.05)$ and the normal controls $(U=$ 9; $p<0.0001)$.

There were no significant differences in the ILL scores of the normal and the anxiety disorder groups.

Finally, we computed correlations between the degree of formal thought disorder, chronological and verbal age, and IQ variables. Over the whole population, there were neither significant correlations between chronological age (CA) and total FTD scores, nor CA age and ILL or LA scores. There were significant negative correlations between verbal age (VA) and both ILL scores $\left(r_{\mathrm{VA} / \mathrm{ILL}}=-0.47\right.$ $p<0.001)$ and LA $\left(r_{\mathrm{VA} / \mathrm{LA}}=-0.37 ; p<0.01\right)$. In other words, the younger the verbal age, the higher the FTD scores. We examined verbal, performance, and full-scale IQ scores, as well as WISC-Kaufman factors (distractibility, verbal comprehension, and perceptual organization) in the entire sample and within diagnostic groups. There were significant negative correlations between full-scale IQ and

Table 4. Percentages of Children that Received at Least One AND MORE THAN Two RATINGS FOr ILL AND LA PER DiAgNOSTIC GROUP

\begin{tabular}{|c|c|c|c|c|c|}
\hline & \multirow[b]{2}{*}{ Ratings for: } & \multicolumn{2}{|c|}{ Illogical thinking } & \multicolumn{2}{|c|}{ Loose associations } \\
\hline & & at least one & more than two & at least one & more than two \\
\hline $\mathrm{AD}$ & & $100 \%$ & $92 \%$ & $71 \%$ & $35.7 \%$ \\
\hline MCDD & & $96 \%$ & $90 \%$ & $65 \%$ & $35.0 \%$ \\
\hline ADHD & & $100 \%$ & $92 \%$ & $42 \%$ & $7.6 \%$ \\
\hline ANX & & $70 \%$ & $60 \%$ & $0 \%$ & $0 \%$ \\
\hline Normal Controls & & $33 \%$ & $13 \%$ & $0 \%$ & $0 \%$ \\
\hline
\end{tabular}

Note. The results of the total The Kiddie Formal Thought Disorder (K-FTD) scores are presented in tables 4, 5, and 6. We found significant main effects $\left(\chi^{2}=44.60 ; p<0.0001\right)$ for diagnosis in the total FTD scores. Significant differences occurred across the groups for both ILL $\left(\chi^{2}=40.69 ; p<0.0001\right)$ and LA $\left(\chi^{2}=27.75 ; p<0.0005\right)$.

ILL = illogical thinking; LA = loose associations; $\mathrm{AD}=$ autistic disorder; $\mathrm{MCDD}=$ multiple complex developmental disorders; ADHD = attention-deficit/hyperactivity disorder; $\mathrm{ANX}=$ anxiety disorders. 
TABLE 5. TOTAL K-FTDS SCORESa

\begin{tabular}{lccc}
\hline & Mean & SD & Cases \\
\hline AD & 0.55 & 0.29 & 14 \\
MCDD & 0.46 & 0.26 & 20 \\
ADHD & 0.25 & 0.16 & 13 \\
ANX & 0.11 & 0.09 & 10 \\
Normal Controls & 0.04 & 0.06 & 15 \\
\hline
\end{tabular}

K-FTDS $=$ The Kiddie Formal Thought Disorder Rating Scale; $\mathrm{AD}=$ autistic disorder; $\mathrm{MCDD}=$ multiple complex developmental disorders; ADHD = attentiondeficit/hyperactivity disorder; ANX = anxiety disorders; $\mathrm{SD}=$ standard deviation .

aKruskal-Wallis one-way ANOVA: $\chi^{2}=44.60$; $p<0.0000$; Mann-Whitney U: AD, MCDD > ADHD $>$ ANX $=$ Normal Controls.

both ILL $\left(r_{\mathrm{TIO} / \mathrm{ILL}}=-0.54 ; p<0.001\right)$ and LA $\left(r_{\mathrm{TIQ} / \mathrm{LA}}=-0.32 ; p<0.05\right)$. Within the IQ components, verbal $\left(r_{\mathrm{VIO} / \mathrm{ILL}}=-0.56 ; p<0.001\right)$ and performance IQ $\left(r_{\mathrm{PIQ} / \mathrm{LA}}=-0.33 ; p<\right.$ $0.05)$ both correlated with ILL, but LA scores correlated only with the verbal IQ $\left(r_{\mathrm{VIQ} / \mathrm{LA}}=\right.$ $-0.36 ; p<0.005)$.

Verbal age and IQ, did not correlate in a significant manner for any one of the diagnostic groups taken alone, however.

Finally, we found no significant correlations between WISC-IQ Kaufman factors and FTD scores within diagnostic groups or across the sample.

TABle 6. RATINGS FOR IllogicAl THINKINGa (ILL)

\begin{tabular}{|c|c|c|c|}
\hline & Mean & $S D$ & Cases \\
\hline $\mathrm{AD}$ & 0.42 & 0.23 & 14 \\
\hline MCDD & 0.34 & 0.23 & 20 \\
\hline $\mathrm{ADHD}^{\mathrm{c}}$ & 0.20 & 0.08 & 13 \\
\hline$A N X^{b}$ & 0.11 & 0.09 & 10 \\
\hline Normal Controls ${ }^{d}$ & 0.04 & 0.06 & 15 \\
\hline
\end{tabular}

$\mathrm{AD}=$ autistic disorder; $\mathrm{MCDD}=$ multiple complex dimensional disorders; ADHD = attention-deficit / hyperactivity disorder; ANX = anxiety disorders; $\mathrm{SD}=$ standard deviation

aKruskal-Wallis one-way ANOVA: $\chi^{2}=40.69$; $p<0.0001$; Mann-Whitney U: AD, MCDD > ADHD $>$ ANXIETY D $=$ Normal Controls ADHD $>$ ANX $=$ Normal Controls.

$\mathrm{b}_{p}<0.05$.

cp $<0.001$.

$\mathrm{d} p<0.0001$.
TABle 7. RATiNGS FOR LoOSE Associationsa (LA)

\begin{tabular}{lccc}
\hline & Mean & SD & Cases \\
\hline AD & 0.13 & 0.12 & 14 \\
MCDD & 0.46 & 0.17 & 20 \\
ADHD & 0.04 & 0.16 & 13 \\
ANX & 0.00 & 0.00 & 10 \\
Normal Controls & 0.00 & 0.00 & 15 \\
\hline
\end{tabular}

$\mathrm{AD}=$ autistic disorder; $\mathrm{MCDD}=$ multiple complex dimensional disorders; ADHD $=$ attention-deficit $/$ hyperactivity disorder; ANX = anxiety disorders; $\mathrm{SD}=$ standard deviation.

aKruskal-Wallis one-way ANOVA: $\chi^{2}=27.75$; $p<0.0005$; Mann-Whitney U: AD, MCDD (U = 140.0; $p=1.0000) \mathrm{AD}>\mathrm{ADHD}(\mathrm{U}=47.0$ two-tailed; $p<0.03)$ $\mathrm{McDD}>\mathrm{ADHD}(\mathrm{U}=76.0$ two-tailed; $p<0.04)$.

\section{DISCUSSION}

In this study, the Kiddie Formal Thought Disorder Rating Scale (Caplan et al. 1989) proved to be a reliable instrument to assess FTD in late latency-aged children. Though some signs of thought disorder were found in all groups of children, the base rate of FDT appeared to be low in relation to the amount of verbal production elicited.

Similar to Caplan et al.'s findings (2000, 2001, 2002), none of the children showed signs of negative FTD (incoherence or poverty of speech). The total FTD scores, therefore, reflected the presence of signs of positive FTD (illogical thinking and loose association). The FTD scores of the anxiety disorder and normal groups were below the cut-point described in Caplan et al. (1989) but above it in children with autistic disorder, MCDD, and ADHD. Moreover, the overall FTD scores in the highfunctioning autistics and MCDD appeared to be significantly higher than the three control groups. Whereas Caplan et al. (1992, 2001, 2002) found loose associations only in children with schizophrenia spectrum disorders, we found this form of thought disorder exclusively in the PDD groups (and, incidentally, in ADHD).

Between the autism and MCDD groups, the sample size is too small to formulate definitive conclusions. Given a power level of 0.14 , one simply cannot conclude from the 
study's findings that children with MCDD and autistic children have similar formal thought disorder scores. To reach a power level of 0.80 a group, we would have needed a sample size of at least $140 \mathrm{MCDD}$ and 156 children with autism.

Although we found no significant differences between the two PDD groups with regard to the type of FTD, the autistic subjects had higher mean scores for both ILL and LA than the MCDD group. As both groups did not differ significantly on cognitive measures (full-scale and verbal IQ), we conclude that more ILL and LA probably reflects increased severity of psychopathology in the autistic group, thus supporting our hypothesis that autistic and MCDD children are on a continuum of severity within the autism spectrum disorder category.

Our supposition, based on findings in autistic adults (Rumsey et al. 1986) and adolescents (Dykens et al. 1991), that the autistic subjects would merely display negative FTD was not confirmed. In our sample of high-functioning late-latency autistic children, we found positive- but no negative-signs of FTD. This may be explained by age or developmental effects, as adults with autism are also characterized by more passive types of social interaction patterns (Howlin et al. 2004).

Regarding the association of FTD with age, cognition, and language, the negative and significant correlation of FTD scores with both verbal age and verbal IQ across all the study groups suggests that FTD reflects immature and underdeveloped verbal processing and verbal skills. However, these correlations were not statistically significant within each of the different diagnostic groups, and this finding might reflect the small sample size of each of the study groups. If replicated on a larger sample of children, these findings imply that formal thought disorder in late latency might be related to the presence and type of psychopathology rather than merely to cognitive immaturity.

The question of how specific these findings are for our target PDD groups must also be considered with great caution in light of the study's small sample size. Nevertheless, for- mal thought disorder, once regarded as typical for schizophrenia (Kraepelin 1896; Bleuler 1950), appears to be common in other conditions. The components of thought disorder, however, are qualitatively different. For instance, flight of ideas and loose associations are common to mania, whereas other forms are rare, and are more common in schizophrenia (Jampala et al. 1989). ILL is seen in normal children under 7 years of age and in some children up to 10 years of age (Arboleda and Holzman 1985; Caplan et al. 2000), in children with ADHD (Caplan et al. 2001), children with epilepsy (Caplan et al. 2002), and, as demonstrated in this study, in children with MCDD, autistic disorder, and ADHD.

This study has limitations that should be considered when interpreting the results. Firstly, few children were included in each target group. Future studies will have to be conducted by a multicenter team in order to recruit enough individuals to gain the level of power required. Secondly, the children were classified into large diagnostic categories. From a genetic point of view, however, there is increasing evidence for overlap between clinical nosological categories at the component level (Grigorenko and Pauls 2003; State et al. 2002). For example, there is some evidence for a genetic overlap between the attention deficits of individuals with ADHD and those with autism spectrum disorders (Bakker et al. 2003). Thus, diagnostic comorbidities, attention characteristics, and language skills should to be considered even more explicitly in future studies of thought disorder in children with autism spectrum disorders.

\section{CONCLUSION}

From the clinical perspective, thought disorder is not specific for schizophrenia, and its presence in children with autism spectrum disorders, including autistic disorder and MCDD, does not support a schizophrenia diagnosis. Rather than representing psychosis, FTD in these PDD groups is another facet of the impaired development of communication found in children with these disorders. The poor 
topic maintenance that is often part of the pragmatic language difficulties in children with autism, autism spectrum disorder, and even in children with ADHD is termed loose association in the parlance of thought disorder research, but the implications are thus quite different. Recent magnetic resonance imaging (MRI) evidence suggests a possible role of the nucleus accumbens (a subcortical hub for gating the flow of information) in thought disorder (Ballmaier et al. 2004). Primary information-processing deficits might be involved in the persistence of formal thought disorder in children with a mental age beyond 7 years. Such information-processing deficits might also underlie the link shared by children with complex developmental disorders, such as autism, MCDD (Kemner et al. 1999), and other psychiatric disorders.

This study contributes to our understanding of some of the clinical problems these children pose. For example, their illogical thinking might distort their perception of the social events they encounter in daily life. These distortions, and their inability to communicate in a clear manner, could foster the affective deregulations so characteristic of children with MCDD and autism. Professionals will have to educate parents and teachers that some of the behavioral problems their children have might reflect their disorganized thinking and associated information-processing, cognitive, and linguistic deficits rather than purposeful, negative acts.

More naturalistic studies on the effects of formal thought disorder in daily life will need to be conducted. These and future studies on the relationship between thought disorder and other discourse and pragmatic measures in children (with pervasive) developmental disorders, the possible contribution of pharmacological agents to the clinical management of FTD, and FTD as a possible predictor of a future psychotic breakdown will need to be wellcontrolled, multicenter, prospective, longitudinal studies. Hopefully, different research groups interested in these difficult-to-classify cases, yet so prominent in clinical practice, will join forces. Agreement will have to be reached on heuristic criteria to enable open communication between the different groups, and to foster multicenter research projects.

\section{REFERENCES}

Andreasen NC: Thought, language, and communication disorders. Arch Gen Psychiatry 36:13151321, 1979.

Andreasen N, Tsuang MT, Canter A: The significance of thought disorder in diagnostic evaluations. Comp Psychiatry 15:27-34, 1974.

Asperger H: Die 'autistische Psychopathen' im Kindesalter. Archiv für Psychiatrie un Nervenkrankheiten 117:76-136, 1944.

Arboleda C, Holzman PS: Thought disorder in children at risk for psychosis. Arch Gen Psychiatry 42:1004-1013, 1985.

Bakker SC, van der Meulen EM, Buitelaar JK, Sandkuijl LA, Pauls DL, Monsuur AJ, van 't Slot R, Minderaa RB, Gunning WB, Pearson PL, Sinke RJ: A whole-genome scan in 164 Dutch sib pairs with attention-deficit/hyperactivity disorder: Suggestive evidence for linkage on chromosomes $7 p$ and 15q. Am J Hum Genet 72(5):1251-1260, 2003.

Ballmaier M, Toga AW, Siddarth P, Blanton RE, Levitt JG, Lee M, Caplan R: Thought disorder and nucleus accumbens in childhood: A structural MRI study. Psychiatry Res 130(1):43-55, 2004.

Baron-Cohen S: Social and pragmatic deficits in autism: Cognitive or affective? J Autism Dev Disord 18(3):379-403, 1988.

Bemporad JR, Smith HF, Hanson G, Cicchetti D: Borderline syndromes in childhood: Criteria for diagnosis. Am J Psychiatry 139(5):596-602, 1982.

Bleuler E: Dementia Praecox or the Group of Schizophrenias. New York, International Universities Press, 1911/1950.

Blöte AW, Curfs LMG: Het gebruik van de Conners Teacher Rating Scale in Nederland. Enige psychometrische gegevens. Nederlands Tijdschrift voor Psychologie 5:226-236, 1986.

Buitelaar JK, Van der Gaag RJ: Diagnostic rules for children with PDD-NOS and multiple complex developmental disorder. J Child Psychol Psychiatry 39(6):911-919, 1998.

Caplan R: Thought disorder in childhood. J Am Acad Child Adolsec Psychiatry

Caplan R, Guthrie D, Fish B, Tanguay PE, DavidLando G: The Kiddie Formal Thought Disorder Scale (K-FTDS). Clinical assessment, reliability, and validity. J Am Acad Child Adolsec Psychiatry 28:408-416, 1989.

Caplan R, Guthrie D, Foy JG: Communication deficits and formal thought disorder in schizophrenic children. J Am Acad Child Adolsec Psychiatry 31:151-159, 1992. 
Caplan R, Guthrie D, Tang B, Komo S, Asarnow RF: Thought disorder in childhood schizophrenia: Replication and update of concept. J Am Acad Child Adolsec Psychiatry 39:771-778, 2000.

Caplan R, Guthrie D, Tang B, Nuechterlein KH, Asarnow RE: Thought disorder in attentiondeficit/hyperactivity disorder. J Am Acad Child Adolesc Psychiatry 40(8):965-972, 2001.

Caplan R, Guthrie D, Komo S, Siddarth P, Chayasirisobhon S, Kornblum H, Sankar R, Hansen R, Mitchell W, Shields WD: Social communication in children with epilepsy. J Child Psychol Psychiatry 43:245-253, 2002.

Cohen DJ, Towbin KE, Mayes L, Volkmar F: Developmental Psychopathology of Multiplex Developmental Disorder. In: Developmental Follow-up: Concepts, Genres, Domains, and Methods. Edited by Friedman SL, Haywood HC, 1991.

Cohen DJ, Volkmar FR, Paul R: Issues in the classification of pervasive developmental disorders: History and current status of nosology. J Am Acad Child Psychiatry 25(2):158-161, 1986.

Cohen J: Weighted kappa: Nominal scale agreement with provision for scaled disagreement of partial credit. Psychol Bull 70:213-230, 1968.

Dahl EK, Cohen DJ, Provence S: Clinical and multivariate approaches to the nosology of pervasive developmental disorders. J Am Acad Child Psychiatry 25(2):170-180, 1986.

Docherty NM, Gordiner SW: Immediate memory and communication disturbances in schizophrenia patients and their relatives. Psychol Med 29: 189-197, 1999.

Dykens E, Volkmar F, Glick M: Thought disorder in high-functioning autistic adults. J Autism Dev Disord 21(3):291-301, 1991.

Green J, Jones B: In-patient child psychiatry: Modern practice, research, and the future. London, Routledge, 1998.

Grigorenko EL, Pauls DL: Analytical methods applied to psychiatric genetics. Meth Mol Med 77: 23-61, 2003.

Howlin P, Goode S, Hutton J, Rutter M: Adult outcome for children with autism. J Child Psychol Psychiatry 45(2):212-229, 2004.

Holzman PS, Shenton ME, Solovay MR: Quality of thought disorder in differential diagnosis. Schizophr Bull 12(3):360-372, 1986.

Jampala VC, Taylor MA, Abrams R: The diagnostic implications of formal thought disorder in mania and schizophrenia: A reassessment. Am J Psychiatry 146(4):459-463, 1989.

Jansen LM, Gispen-de Wied CC, van der Gaag RJ, Van Engeland H: Differentiation between autism and multiple complex developmental disorder in response to psychosocial stress. Neuropsychopharmacology 28(3):582-590, 2003.

Kaufman AS: Intelligence testing with the WISC-R. New York, John Wiley \& Sons, 1979.
Kemner C, van der Gaag RJ, Verbaten M, Van Engeland H: ERP differences among subtypes of pervasive developmental disorders. Biol Psychiatry 46(6):781-789, 1999.

Kinney DK, Holzman PS, Jacobsen B, Faber B, Hildebrand W, Kasell E, Zimbalist ME: Thought disorder in schizophrenic and control adoptees and their relatives. Arch Gen Psychiatry 54:475479, 1997.

Kolvin I, Ounsted C, Humphrey M, McNay A: The phenomenology of childhood psychoses. $\mathrm{Br} \mathrm{J}$ Psychiatry 118:385-395, 1971.

Kraeplin E: Psychiatrie: Ein Lehrbuch für Studierende und Arzte. Leipzig: Barth, 1896.

Lecours AR, Vanier-Clément M: Schizophasia and jargonahasia. Brain Lang 3:516-565, 1976.

Miller JN, Ozonoff S: Did Asperger's cases have Asperger disorder? A research note. J Child Psychol Psychiatry 38(2):247-251, 1997.

Nagy J, Szatmari P: A chart review of schizotypal personality disorders in children. J Autism Dev Disord 16(3):351-367, 1986.

Pine F: On the concept "borderline" in children. A clinical essay. Psychoanalytic Study of the Child 29:341-368, 1974

Prior M, Perry D, Gajzago C: Kanner's syndrome or early-onset psychosis: A taxonomic analysis of 142 cases. J Autism Childhood Schizophr 5:71-80, 1975.

Rumsey JM, Andreasen NC, Rapoport JL: Thought, language, communication, and affective flattening in autistic adults. Arch Gen Psychiatry 43: 771-777, 1986.

Russell AT, Bott L, Sammons C: The phenomenology of schizophrenia occurring in childhood. J Am Acad Child Adolesc Psychiatry 28(3):399-407, 1989.

State MW, Lombroso PJ, Pauls DL, Leckman JF: The genetics of childhood psychiatric disorders: A decade of progress. J Am Acad Child Adolesc Psychiatry 39(8):946-962, 2000.

Towbin KE, Dykens EM, Pearson GS, Cohen DJ: Conceptualizing "borderline syndrome of childhood" and "childhood schizophrenia" as a developmental disorder. J Am Acad Child Adolesc Psychiatry 32(4):775-782, 1993.

Van Engeland H, Van der Gaag RJ: McDD in childhood: A precursor of schizophrenic spectrum disorder. Schizophr Res 11:197, 1994.

Van der Gaag RJ: Multiplex developmental disorders: An exploration of the borderlines on the autistic spectrum. Ph.D. thesis. University of Utrecht, The Netherlands, 1993.

Van der Gaag RJ, Buitelaar J, Van den Ban E, Bezemer M, Njio L, Van Engeland H: A controlled multivariate chart review of multiple complex developmental disorder. J Am Acad Child Adolesc Psychiatry 34(8):1096-1106, 1995.

Vela RM, Gottlieb H, Gottlieb E: Borderline syndromes in childhood: A critical review. In: The 
Borderline Child: Approaches to Etiology, Diagnosis, and Treatment. Edited by Robson KS. New York, McGraw-Hill, 1983, pp 31-48.

Verhulst FC: Mental Health in Dutch Children. Rotterdam, Dissertation Erasmus Universiteit, 1985.

Volkmar FR, Cohen DJ: Comorbid association of autism and schizophrenia. Am J Psychiatry 148: 1705-1707, 1990.

Vollema MG, van den Bosch RJ: The multidimensionality of schizotypy. Schizophr Bull 21(1): 1931, 1995.

Watson L: Pragmatic abilities and disabilities of autistic children. In: Language and treatment of autistic and developmentally disorder children. Edited by Layton TL. Springfield (Illinois), Charles C. Thomas, 1988, pp. 89-127.
Wing Asperger's syndrome: A clinical account. Psychol Med 11:115-129, 1981.

Wolff S: Loners: The Life Path of Unusual Children. Routledge, 2003.

Address reprint requests to: Rutger J. Van der Gaag UMCN St Radboud-ACKJON Reinier Postlaan 12 6525 GC Nijmegen The Netherlands

E-mail: R.vanderGaag@psy.umcn.nl 